Research Article

\title{
Identification of Permanent Faults and Disturbance Induced by Deicing Based on Permutation Entropy for the Large-Scale Clean Energy Transmission in Winter
}

\author{
Yunlong Wang $\mathbb{D}$, Tiejun Tang, Xiang Ju, and Dingding Hong \\ Kunming Branch of EVC CSG, Kunming 650000, China \\ Correspondence should be addressed to Yunlong Wang; 041603@ymu.edu.cn
}

Received 6 May 2021; Revised 24 May 2021; Accepted 1 June 2021; Published 21 June 2021

Academic Editor: Bo Yang

Copyright ( $) 2021$ Yunlong Wang et al. This is an open access article distributed under the Creative Commons Attribution License, which permits unrestricted use, distribution, and reproduction in any medium, provided the original work is properly cited.

\begin{abstract}
Ice shedding may induce isolated ground wires' temporary grounding, which can cause electric quantities of direct current (DC) deicing devices to fluctuate. Hence, the disturbance of ice shedding is able to trigger the protective relay frequently and unnecessarily, which adversely affects the deicing process. Due to the randomness of ice shedding, the grounding resistance varies quickly; thus, the disturbance in poles of deicing devices can be detected multiple times in a short time. Moreover, the permanent fault requires steady arc plasma because of the low output voltage and current of deicing devices, which cannot bring out multipletime disturbances in the poles. This paper proposes the identification of permanent faults and disturbance induced by deicing based on the permutation entropy, which is verified by a large number of simulations.
\end{abstract}

\section{Introduction}

The ground wire is usually applied for the lightning shield and communication, which transmits little energy. Therefore, the cold rain in the plateau may induce ice freezing along the ground wire. If there is no operation to melt or eliminate ice along the ground wire, ice may be too heavy, which exceeds the affordability of ground wires. Actually, the tower destruction caused by heavy ice is the severest problem in the extreme weather in winter. In order to decrease the adverse effect of the ice freezing in ground wires, the deicing device is widely equipped in China.

In the process of deicing, melting ice drops from the ground wire. Melting ice can significantly reduce the isolation between the ground wire and transmission lines; hence, the discharge may occur if transmission lines are still transmitting the energy. The swing of transmission lines induced by ice melting is analyzed in the experiment environment in [1-5]. Zhuang et al. and Nie et al. $[6,7]$ applied a trend prediction model for the ice freezing and development of deicing based on the micrometeorology monitor. The cause and the process of deicing faults are studied in [8-20], and the reinforcement of isolators of transmission lines is proposed.
The filter is usually unset for the DC deicing device, so there are a large number of high-frequency harmonics in the output voltage. Furthermore, the disturbance induced by deicing cannot be detected by time-frequency domain methods, e.g., the wavelet and the short-window Fourier transformation. This paper analyzes the difference of circuits between the disturbance and the fault induced by deicing, and the permutation entropy is employed to obtain the trend of the waveform. At last, the variance is utilized to identify the disturbance and the fault by weighing the complexity of permutation waveforms.

\section{Permutation Entropy Identification Method for Deicing Disturbance and Fault of the Ice-Melting Line}

2.1. Permutation Entropy Algorithm. Permutation entropy is a numerical calculation method to estimate the dynamic mutation and stochastic time series. It can quantitatively evaluate the random noise contained in the time series and detect the sudden change which is different from the noise. It can obtain a higher resolution, the output results of its 
calculation are clear, and the prominent information can be intuitively identified $[21,22]$.

Let a time series be $X(i), i=1,2,3, \ldots, n$; then, the time series is reconstructed in the phase space, and the resulting matrix is

$$
Z=\left[\begin{array}{cccc}
x(1) & x(1+t) & \cdots & x(1+(d-1) t) \\
x(2) & x(2+t) & \cdots & x(2+(d-1) t) \\
x(j) & x(j+t) & \cdots & x(j+(d-1) t) \\
\vdots & \vdots & & \vdots \\
x(k) & x(k+t) & \cdots & x(k+(d-1) t)
\end{array}\right] .
$$

In the formula, $j=1,2, \ldots, k, k$ is the number of rows in the matrix, $d$ is the embedded digit capacity, $t$ is the delay time, and $k=n-(d-1) t$. Every row $\{x(j), x(j+t), \ldots$, $x(j+(d-1) t)\}$ in the matrix can be regarded as a reconstructed component, and there are a total of $k$ reconstructed components. The elements of each reconstructed component are arranged in the ascending order according to their numerical size; $j_{1}, j_{2}, \ldots, j_{d}$ denote the index of the column of each element in the reconstructed component; that is,

$$
x\left(i+\left(j_{1}-1\right) t\right) \leq x\left(i+\left(j_{2}-1\right) t\right) \leq \cdots \leq x\left(i+\left(j_{d}-1\right) t\right) .
$$

If there are equal values in the reconstructed components, which are

$$
x\left(i+\left(j_{1}-1\right) t\right)=x\left(i+\left(j_{2}-1\right) t\right),
$$

at this time, they are sorted according to the subscript $i$ of $j_{i}$. For each row of the matrix reconstructed by any time series $X(i)$, a group of symbol sequences can be obtained:

$$
S(l)=\left(j_{1}, j_{2}, \cdots, j_{d}\right) .
$$

In the formula, $l=1,2, \ldots, k$, and $k \leq d$ !, $d$-dimensional phase space maps different symbol sequences $\left(j_{1}, j_{2}, \ldots, j_{d}\right)$, and there are $d$ ! kinds. The symbol sequence $S(l)$ is one of these permutations. If the probability of $k$ different symbol sequences appearing is $P_{1}, P_{2}, \ldots, P_{k}$, the permutation entropy can be defined as

$$
H_{P}(d)=-\sum_{j=1}^{k} P_{j} \ln P_{j} .
$$

Normalize $H_{P}(d)$, and the results are as follows:

$$
0 \leq H_{P}=\frac{H_{P}}{\ln (d !)} \leq 1 .
$$

The magnitude of the $H_{P}$ value indicates the randomness of the time series $X(i)$. The larger the $H_{P}$ value is, the more complex and random the time series will be; the smaller the $H_{P}$ value is, the more orderly and regular the time series will be. Besides, the $H_{P}$ waveform can be used to reflect the mutation degree of time series $X(i)$.

2.2. Variance Analysis of the Permutation Entropy Waveform of the Output DC Voltage of the Ice-Melting System. Variance is often used to measure the degree of deviation between a random variable and its mathematical expectations, and the variance calculation can be used to further verify the degree of randomness, dispersion, and mutation of the DC voltage permutation entropy waveform. Assuming that $X$ is a discrete random variable, the calculation formula of variance of the discrete random variable is as follows:

$$
D(X)=E\left((X-E(X))^{2}\right)=E\left(X^{2}\right)-E^{2}(X) .
$$

In the formula, $E(X)$ is the expected value; $X$ is the value of the variable. The larger the variance is, the greater the fluctuation of the data is and the more unstable and discrete it is. The smaller the variance is, the smaller the fluctuation of the data is and the more stable it is. In the ice-melting process of the ice-melting device, the variance of the DC voltage permutation entropy obtained when the negative pole of the deicing line has a disturbance and a permanent fault is calculated, and the results can be characterized such that, in the process of disturbance, the overall voltage fluctuation range is large and its variance is large, while in the case of permanent fault, the overall voltage variation law tends to be stable, the fluctuation is small, and the variance is small. According to this characteristic, permanent faults and disturbances can be identified. At present, the protection delay of DC melting ice can reach hundreds of milliseconds, so it takes a long time to identify the disturbance and permanent fault in the process of DC melting ice.

The fault type can be confirmed by the following criteria:

$$
\begin{cases}D(X) \geq D_{t h}, & \text { disturbance, } \\ D(X)<D_{t h}, & \text { fault. }\end{cases}
$$

In this formula, $D_{t h}$ is the variance threshold.

\section{Simulation Modeling}

Taking the DC ice-melting system of Kunbei Converter Station as an example, a simulation model is built in PSCAD/EMTDC. The overall structure is shown in Figure 1, and the parameters of relevant components are shown in Table 1 [23-25].

The 12-pulse converter consists of two six-pulse threephase bridge fully controlled rectifiers. For one of the threephase bridge fully controlled rectifiers, the structure is shown in Figure 2. There are six thyristors in total. The top three thyristors are the common cathode group, and the bottom three thyristors are the common anode group. Two thyristors need to conduct at the same time at each time, one in the common cathode group and the other in the common anode group, and cannot be in the same phase. The pulses of six thyristors conduct in the order of $1 \sim 6$ as shown in Figure 2, and the trigger phase difference is $60^{\circ}$. The output voltage of each cycle has 6 pulsations, and the waveform of each pulsation is the same, so it is a 6-pulse rectifier circuit. The 12pulse converter valve is also the 12-pulse rectifier circuit.

\section{Simulation Cases}

4.1. Disturbance in the Ice-Melting Line. Set up that when the disturbance occurs, the short-circuit fault is located at $20 \mathrm{~km}$ from the rectifying device to the negative ice-melting line. A 
TABle 1: Parameters of each element of the ice-melting system of the converter station.

\begin{tabular}{lc}
\hline Element & Parameter \\
\hline AC power supply & $500 \mathrm{kV}$ \\
Step-down transformer & $500 \mathrm{kV} / 38.5 \mathrm{kV}$ \\
AC filter & $20 \mathrm{MVar}$ \\
Three-winding converter & $35 \mathrm{kV} / 15 \mathrm{kV} /$ \\
transformer & $15 \mathrm{kV}$ \\
Rated current of the 12-pulse & $4.5 \mathrm{kA}$ \\
converter valve & \\
Rated voltage of the 12-pulse & $20 \mathrm{kV}$ \\
converter valve & $0.025 \mathrm{H}$ \\
Smoothing reactor & $70 \mathrm{~km}$ \\
Length of the ground wire & $0.2 \Omega$ \\
Unit length resistance of the ground wire: $R$ & $0 \sim 1000 \Omega$ \\
Range of the resistance of the disturbance &
\end{tabular}

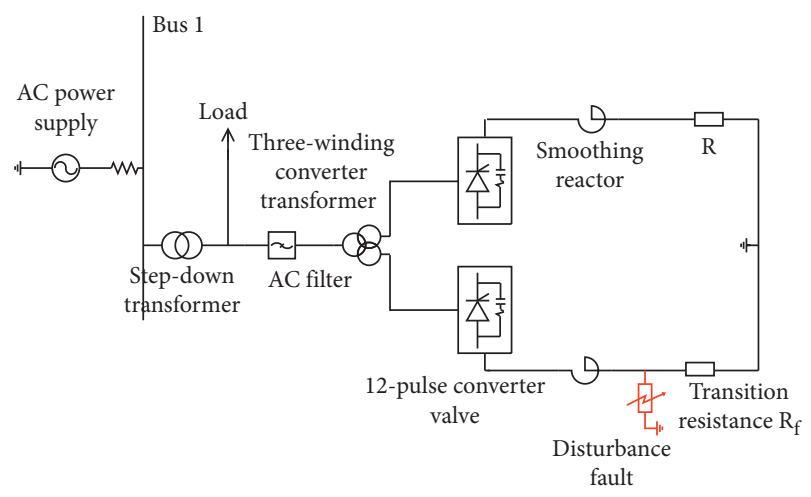

FIgURE 1: Overall structure diagram of the ice-melting system.

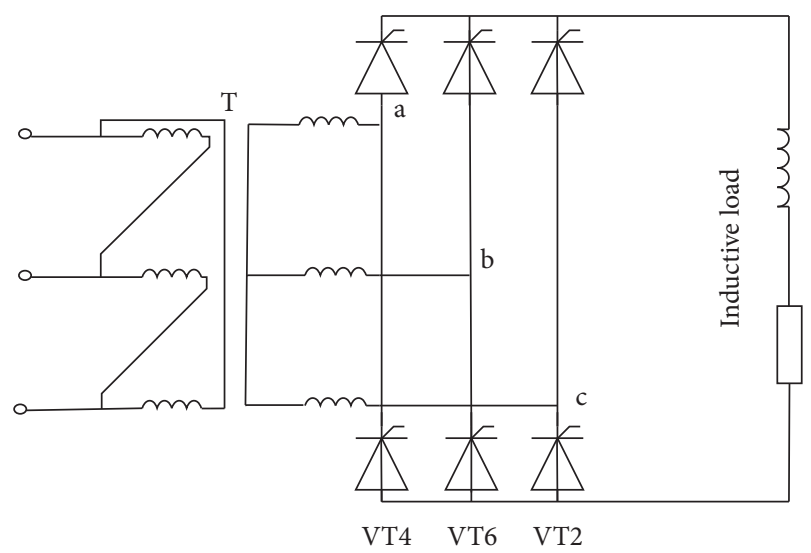

FIgURE 2: Three-phase bridge fully controlled rectifier circuit.

set of deicing circuit disturbance transition resistances varying with thawing time is randomly set, and the corresponding icemelting voltage waveform can be obtained, as shown in Figure 3. Permutation entropy is calculated for the negative poles of the perturbation, and the results are shown in Figure 4.

By analyzing the graphics and simulation results, one can get the following: in the process of ice melting, disturbance may occur when the line deicing, resulting in a short-time grounding short circuit. However, the change of the resistance value caused by deicing will lead to many sudden changes of ice-melting voltage in a short time. In Figure 3, set in the

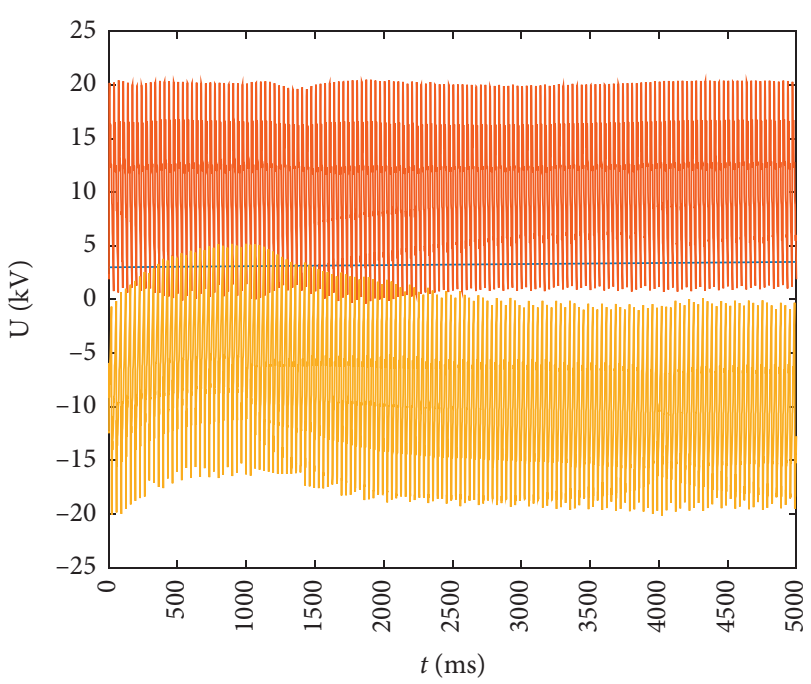

FIGURE 3: Ice-melting voltage waveform of the random disturbance fault.

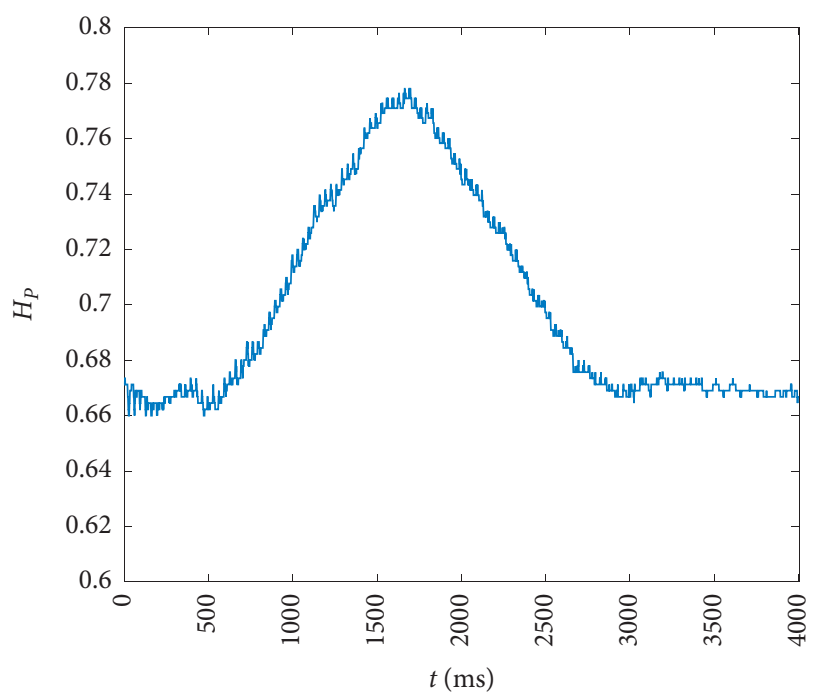

Figure 4: Permutation entropy waveform of thawing voltage for random disturbance faults.

negative pole due to the short-circuit fault, so the negative icemelting voltage is particularly obvious, the change of the positive ice-melting voltage is relatively small, and it can be approximately ignored. There are a lot of high-frequency mutations in the output voltage of the DC ice-melting device due to harmonic influence; therefore, it is difficult to extract the disturbance directly from the waveform. However, disturbances can be easily detected from harmonics by using permutation entropy. The waveform variance calculated in Figure 4 is 0.014 according to equation (7).

4.2. Permanent Failure of the Ice-Melting Line. Set up that the permanent fault is located $5 \mathrm{~km}$ away from the negative pole of the ice-melting device, and the resulting ice-melting voltage waveform is shown in Figure 5. The permutation 


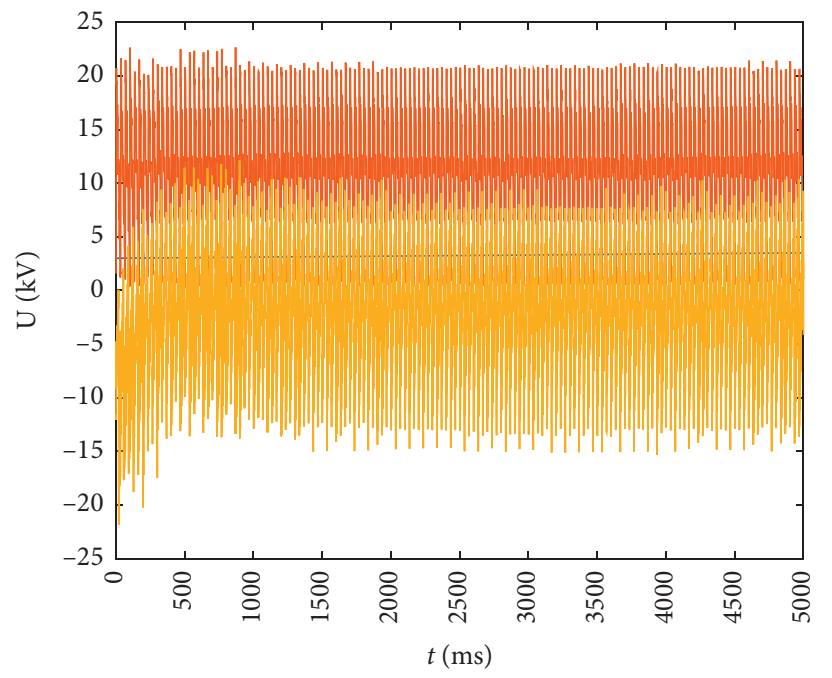

FIGURE 5: Ice-melting voltage waveform for permanent failure at $5 \mathrm{~km}$.

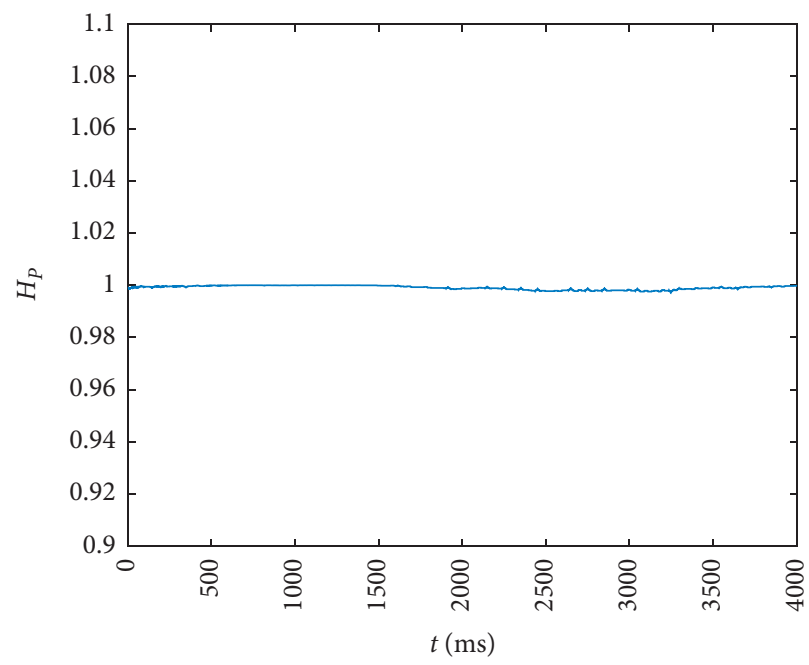

FIGURE 6: Permutation entropy waveform of thawing voltage for the permanent fault at $5 \mathrm{~km}$.

TABle 2: Permanent failure of the ice-melting line.

\begin{tabular}{lccc}
\hline Type & Fault distance $(\mathrm{km})$ & Positive and negative poles & Variance \\
\hline Disturbance & 10 & Negative & 0.013 \\
Disturbance & 25 & Positive & 0.032 \\
Disturbance & 30 & Negative & 0.028 \\
Disturbance & 45 & Positive & 0.021 \\
Disturbance & 50 & Negative & 0.061 \\
Disturbance & 65 & Positive & 0.036 \\
Fault & 15 & Negative & $1.7129 \times 10^{-6}$ \\
Fault & 20 & Positive & $3.2447 \times 10^{-6}$ \\
Fault & 35 & Negative & $1.3610 \times 10^{-4}$ \\
Fault & 40 & Positive & $6.5241 \times 10^{-4}$ \\
Fault & 55 & Negative & $1.4890 \times 10^{-5}$ \\
Fault & 60 & Positive & $7.0781 \times 10^{-5}$ \\
\hline
\end{tabular}


entropy waveform obtained by calculating the fault pole voltage is shown in Figure 6.

When a permanent fault occurs, the transition resistance at the fault point remains constant. The output voltage of the DC ice-melting device is relatively stable, which does not contain the abrupt change outside the harmonic wave. Though its permutation entropy value is large, the value is quite stable compared with the perturbation. The variance calculated according to equation (7) is $6.13 \times 10^{-4}$, which is quite small compared with the disturbance.

In the simulation system shown in Figure 1, set up a variety of faults and disturbances, and then test them. The results are shown in Table 2.

By analyzing the results, the following can be obtained: after the permanent failure of the ice-melting line, the voltage fluctuation is very small, which is greatly different from the disturbance, and the variance of its permutation entropy is stable and less than 0.01 . However, due to the influence of random transition resistance, the output voltage of the DC ice-melting device will change many times under the disturbance condition, and its variance value of permutation entropy is large and easy to distinguish from permanent failures.

\section{Conclusion}

(1) When a deicing disturbance occurs, the voltage waveform of the DC ice-melting device will fluctuate many times, and such voltage fluctuations will not occur for permanent faults due to the stability of the fault point.

(2) Without the suppression of the DC filter, the output voltage of the DC deicing device contains a large number of high-order harmonics, so it is difficult to accurately find the voltage fluctuation caused by disturbance or fault using traditional time-frequency analysis methods.

(3) Through permutation entropy calculation, the voltage fluctuation caused by disturbance and permanent fault can be accurately extracted. Through the variance estimation of permutation entropy calculation results, disturbance and permanent fault can be accurately identified.

\section{Data Availability}

All the data supporting the results of our study are available within the manuscript.

\section{Conflicts of Interest}

The authors declare no conflicts of interest.

\section{Acknowledgments}

This work was supported by the China Southern Power Grid Project (no. 0109002021030103SJ00002).

\section{References}

[1] W. Hao, S. Peng, and J. Lu, "Research on DC ice-melting technologies for $500 \mathrm{kV}$ AC transmission lines," in Proceedings of the 2015 5th International Conference on Electric Utility Deregulation and Restructuring and Power Technologies (DRPT), pp. 1663-1666, Changsha, China, November 2015.

[2] X. Jiang, S. Fan, Z. Zhang, C. Sun, and L. Shu, "Simulation and experimental investigation of DC ice-melting process on an iced conductor," IEEE Transactions on Power Delivery, vol. 25, no. 2, pp. 919-929, 2010.

[3] G. He, Q. Hu, L. Shu et al., "Impact of icing severity on corona performance of glaze ice-covered conductor," IEEE Transactions on Dielectrics and Electrical Insulation, vol. 24, no. 5, pp. 2952-2959, 2017.

[4] L. E. Kollar, M. Farzaneh, and P. Van Dyke, "Modeling ice shedding propagation on transmission lines with or without interphase spacers," IEEE Transactions on Power Delivery, vol. 28, no. 1, pp. 261-267, 2013.

[5] M. Yan, Z. Zhou, J. Wen et al., "Risk assessment method of power grid icing disaster based on short-term icing prediction," Automation of Electric Power Systems, vol. 40, no. 21, pp. 168-175, 2016.

[6] W. Zhuang, C. Qi, J. Wang et al., "Dynamic ice process estimation model of transmission line based on micrometeorological monitoring," Power System Protection and Control, vol. 47, no. 14, pp. 87-94, 2019.

[7] S. Nie, G. Qu, H. Ye, and X. Jiang, "On-line monitoring system for icing state of overhead transmission line," in Proceedings of the 2012 Power Engineering and Automation Conference, pp. 1-5, Bali, Indonesia, September 2012.

[8] F. Jafarishiadeh, F. Mohammadi, and M. Sahraei-Ardakani, "Preventive dispatch for transmission de-icing," IEEE Transactions on Power Systems, vol. 35, no. 5, pp. 4104-4107, 2020.

[9] L. Shunxin, G. Guangsong, Y. Lichao, and Z. Songwei, "Research on conductor icing of overhead transmission lines," in Proceedings of the 2011 International Conference on Consumer Electronics, Communications and Networks (CECNet), pp. 606-609, Xianning, China, April 2011.

[10] Z. Wang, S. He, Q. Li et al., "A full-scale experimental validation of electromagnetic time reversal applied to locate disturbances in overhead power distribution lines," IEEE Transactions on Electromagnetic Compatibility, vol. 60, no. 5, pp. 1562-1570, 2018.

[11] F. Cui, X. Liu, S. Zhang, A. Zhou, and B. Huo, "The impact of interphase spacers on galloping control of three-phase iced eight-bundled transmission lines: an experimental study," IEEE Transactions on Power Delivery, vol. 36, no. 1, pp. 371382, 2021.

[12] S. Xiong, Y. Liu, J. Fang, J. Dai, L. Luo, and X. Jiang, "Incipient fault identification in power distribution systems via humanlevel concept learning," IEEE Transactions on Smart Grid, vol. 11, no. 6, pp. 5239-5248, 2020.

[13] G. Huang, E. F. Fukushima, J. She, C. Zhang, and J. He, "Estimation of sensor faults and unknown disturbance in current measurement circuits for PMSM drive system," Measurement, vol. 137, pp. 580-587, 2019.

[14] M. Parsi and P. A. Crossley, "Optimized time for travelling wave fault locators in the presence of different disturbances based on real-world fault data," IEEE Open Access Journal of Power and Energy, vol. 8, pp. 138-146, 2021.

[15] F. Zhen, M. Site, L. Bo et al., "Design method of modular multilevel real-time on-line anti-icing and ice-melting 
equipment based on self-ice-melting conductors," in Proceedings of the 2019 IEEE 3rd Conference on Energy Internet and Energy System Integration (EI2), pp. 877-882, Changsha, China, November 2019.

[16] Z. Ye, "The application analysis of ice-melting technical measures for OPGW," in Proceedings of the 2018 2nd IEEE Conference on Energy Internet and Energy System Integration (EI2), pp. 1-6, Beijing, China, October 2018.

[17] F. Bin, Z. Lixing, and T. Zhe, "The study on factors influencing the ice-melting performance of transmission line," in Proceedings of the 2013 Fourth International Conference on Intelligent Systems Design and Engineering Applications, pp. 710-713, Zhangjiajie, China, November 2013.

[18] C. Wang, J. Wen, S. Li, X. Ma, and J. Wang, "Design on DC de-icing schemes for high voltage transmission line," in Proceedings of the 2010 5th International Conference on Critical Infrastructure (CRIS), pp. 1-5, Beijing, China, September 2010.

[19] H. Yang and Y. Chen, "Analysis of line deicing jump fault," Transactions of China Electrotechnical Society, vol. 10, pp. 102-103, 2017.

[20] B. Niu, C. Wang, and W. Liang, "Application research on antideicing jumping fault measures of $220 \mathrm{kV}$ double circuit line with the same tower," Shanxi Electric Power, vol. 4, pp. 46-48, 2020.

[21] H. Zhang and S. He, "Analysis and comparison of permutation entropy, approximate entropy and sample entropy," in Proceedings of the 2018 International Symposium on Computer, Consumer and Control (IS3C), pp. 209-212, Taichung, Taiwan, December 2018.

[22] A. Dávalos, M. Jabloun, P. Ravier, and O. Buttelli, "Theoretical study of multiscale permutation entropy on finite-length fractional Gaussian noise," in Proceedings of the 2018 26th European Signal Processing Conference (EUSIPCO), pp. 1087-1091, Rome, Italy, September 2018.

[23] H. Zhang, L. Wang, and S. He, "The comparison of several kinds of permutation entropy," in Proceedings of the 2018 International Conference on Intelligent Transportation, Big Data \& Smart City (ICITBS), pp. 432-435, Xiamen, China, January 2018.

[24] X. Chen, Z. Yang, and W. Lou, "Fault diagnosis of rolling bearing based on the permutation entropy of VMD and decision tree," in Proceedings of the 2019 3rd International Conference on Electronic Information Technology and Computer Engineering (EITCE), pp. 1911-1915, Xiamen, China, October 2019.

[25] P. Sun, S. Chen, and S. Zhang, "The study of DC melting ice for overhead ground wire," in Proceedings of the 2011 International Conference on Electronics, Communications and Control (ICECC), pp. 2960-2963, Ningbo, China, September 2011. 